\title{
Hazard interaction analysis for multi-hazard risk assessment: a systematic classification based on hazard-forming environment
}

\author{
Baoyin Liu ${ }^{1}$, Yim Ling Siu ${ }^{1}$, and Gordon Mitchell ${ }^{2}$ \\ ${ }^{1}$ School of Earth and Environment, University of Leeds, Leeds, LS2 9JT, UK \\ ${ }^{2}$ School of Geography, University of Leeds, Leeds, LS2 9JT, UK \\ Correspondence to: Yim Ling Siu (y.1.siu@leeds.ac.uk)
}

Received: 10 November 2015 - Published in Nat. Hazards Earth Syst. Sci. Discuss.: 1 December 2015

Revised: 30 January 2016 - Accepted: 5 February 2016 - Published: 3 March 2016

\begin{abstract}
This paper develops a systematic hazard interaction classification based on the geophysical environment that natural hazards arise from - the hazard-forming environment. According to their contribution to natural hazards, geophysical environmental factors in the hazard-forming environment were categorized into two types. The first are relatively stable factors which construct the precondition for the occurrence of natural hazards, whilst the second are trigger factors, which determine the frequency and magnitude of hazards. Different combinations of geophysical environmental factors induce different hazards. Based on these geophysical environmental factors for some major hazards, the stable factors are used to identify which kinds of natural hazards influence a given area, and trigger factors are used to classify the relationships between these hazards into four types: independent, mutex, parallel and series relationships. This classification helps to ensure all possible hazard interactions among different hazards are considered in multi-hazard risk assessment. This can effectively fill the gap in current multihazard risk assessment methods which to date only consider domino effects. In addition, based on this classification, the probability and magnitude of multiple interacting natural hazards occurring together can be calculated. Hence, the developed hazard interaction classification provides a useful tool to facilitate improved multi-hazard risk assessment.
\end{abstract}

\section{Introduction}

Many world regions are subject to multiple natural hazards. In these areas, the impacts of one hazardous event are often exacerbated by interaction with other hazards (Marzoc- chi et al., 2009). The mechanism by which these interactions occur varies, and may be a product of one event triggering another, or "crowding", where events occur independently without evident common cause, but in close proximity, spatially, temporally, or both (Tarvainen et al., 2006; Carpignano et al., 2009; Marzocchi et al., 2012). Close proximity between events may reduce resilience and recovery, and hence is indicative of greater risk than for events considered in isolation. Multi-Hazard Risk Assessment (MHRA) has developed to combat the limitations of single-hazard appraisal, with MHRA approaches building on those developed for single-hazard risk assessment, but additionally considering hazard interaction (Armonia, 2006; Marzocchi et al., 2009; Di Mauro et al., 2006). The existing research on hazard interaction in MHRA mainly focuses on the domino (cascade) effect, whereby one hazardous event triggers another (e.g. a landslide induced by an earthquake, a flood induced by a storm) (Marzocchi et al., 2012; Frolova et al., 2012). Such studies analyse hazard interaction beginning with given information about the primary hazard, which triggers another or increases the probability of others occurring. Hazard matrix or event tree are the commonly used methods. For example, Kappes et al. (2010) proposed a matrix to identify the possible triggering effect within seven hazards in an Alpine region, whilst Gill and Malamud (2014) analysed 21 hazards using a hazard matrix which focuses on hazard interactions where one hazard triggers another or increases the probability of others occurring. Marzocchi et al. $(2009,2012)$ employed an event tree to analyse multi-hazard risk due to triggering effects in Italy; Frolova et al. (2012) identified technological accidents (fires, explosions, release of chemical materials) triggered by earthquakes according to the distribution 
of shaking intensity in Russia; whilst the MATRIX (New Multi-HAzard and MulTi-RIsK Assessment MethodS for Europe) project (Garcia-Aristizabal and Marzocchi, 2013) adopted event-tree and fault-tree strategies to identify the domino effect scenarios in Naples (volcanic earthquakes and seismic swarms triggered by volcanic activity), Guadeloupe (rainfall- and earthquake-triggered landslides) and Cologne (earthquake-triggered embankment/flood defense dyke failures). Eshrati et al. (2015) also proposed elaboration of event trees as a useful method to analyse the potential consequences of domino effects in more detail by simulating the possible chain of triggering events. However, the interaction between different hazards is complex and dynamic, and the domino effect is not able to cover all situations. For example, two hazards may occur independently without evident common cause, but in close proximity, spatially, temporally or both. Hence, interaction between different natural hazards needs a systematic and comprehensive analysis to facilitate improved MHRA.

This paper therefore aims to develop a systematic hazard interaction classification based on the geophysical environment that gives rise to natural hazards. Based on this classification, all possible interactions among different hazards can be considered, and the probability and magnitude of multiple interacting natural hazards occurring together can be calculated in MHRA. Section 2 introduces a basic definition of hazard-forming environment and its contribution to natural hazard. Section 3 presents a systematic classification of hazard interactions based on hazard-forming environment analysis. Section 4 applies this classification within MHRA to test its utility, and Sect. 5 introduces a case study in China's Yangtze River Delta. Further discussion, including limitations of the approach, is presented in Sect. 6 before drawing a final conclusion in Sect. 7.

\section{Hazard-forming environment}

Natural hazards are a product of geophysical processes and therefore arise from a specific geophysical environment, which includes environmental factors in the atmosphere, hydrosphere, biosphere and lithosphere. These factors are the basic conditions for the occurrence of hazards (Park, 1994; Shi, 1996; McGuire et al., 2002). Natural hazards are also extreme natural events (McGuire et al., 2002; Smith and Petley, 2009). Here, "extreme" means that natural hazards are extraordinary compared to the normal natural event. The "extreme" is always caused by one or more environmental factors' substantial departure in either the positive or the negative direction from their mean value - thus flood can be induced when precipitation is above the normal level, and drought occur when it is below the normal level.

According to their contribution to natural hazard, geophysical environmental factors can be categorized into two types. Factors in the first type form the background for the occur- rence of natural hazards. Here, these factors can be considered as stable factors, which are the preconditions to hazards. These factors never change or change very little over a long time (hundreds or thousands of years), e.g. tectonic plates or landform. Compared to the stable factors, factors in the second type are constantly changing, e.g. daily precipitation and temperature. Substantial changes in these factors give rise to hazard. Therefore, they can be taken as trigger factors for natural hazards and are the factors that determine the frequency and magnitude of hazards. The fundamental characteristics of natural hazards are decided by these geophysical environmental factors. Hence, geophysical environmental factors are the determining factors for natural hazards, and the geophysical environment which consists of these factors can be defined as the "hazard-forming environment". Different combinations of these geophysical environmental factors can induce different hazards. Hence hazard-forming environment analysis is useful in both hazard identification and hazard interaction analysis.

For illustrative purpose, Table 1 lists the relationship between some specific major hazards and their hazard-forming environments. These then are the geophysical environmental (stable and trigger) factors for the most common major natural hazards. They provide a basis for analysing interactions among hazards, which we discuss next.

\section{Hazard-forming environment for hazard interaction analysis}

The geophysical environmental factors in the hazard-forming environment were categorized into two types, stable factors and trigger factors (discussed above). In this section, stable factors are used to identify which kinds of natural hazards influence a given area, and then a systematic classification of hazards interaction is developed to calculate the probability and magnitude of multiple interacting hazards occurring together based on trigger factors.

\subsection{Stable factors for hazard identification}

Hazard identification is used to identify which kinds of natural hazards influence a given area, and hence also the spatial distribution of that hazard. Stable factors act as a precondition for major natural hazards (see above) and according to their characteristics, the type of hazards influencing a given area can be deduced. For example, if a coastal city is located in a tectonically stable platform with low, flat terrain and numerous rivers, then these environmental factors determinate that slow riverine floods, coastal floods and pluvial floods could influence this city, but strong earthquakes, volcanic eruptions, landslides and avalanche are unlikely.

The susceptibility of each (geographical) assessment unit to each hazard can be calculated based on these stable factors. The relationship between stable factors and major natu- 
Table 1. The relationship between some specific major hazards and their hazard-forming environments.

\begin{tabular}{|c|c|c|c|}
\hline Hazard & Definition & Stable factor & Trigger factor \\
\hline Earthquake & $\begin{array}{l}\text { A sudden and violent shaking of } \\
\text { the ground caused by the sudden } \\
\text { breaking and movement of } \\
\text { tectonic plates of the Earth's } \\
\text { crust (Alexander, 1993). }\end{array}$ & $\begin{array}{l}\text { Crustal plate boundary } \\
\text { (Nishenko and Buland, 1987; } \\
\text { Pacheco et al., 1993). }\end{array}$ & $\begin{array}{l}\text { Movement of the Earth's crust } \\
\text { (Nishenko and Buland, 1987; } \\
\text { Pacheco et al., 1993). }\end{array}$ \\
\hline $\begin{array}{l}\text { Volcanic } \\
\text { eruption }\end{array}$ & $\begin{array}{l}\text { A volcanic eruption occurs when magma } \\
\text { and the dissolved gases it contains } \\
\text { are discharged from a volcanic } \\
\text { vent (Blong, 1984). }\end{array}$ & $\begin{array}{l}\text { Crustal plate boundary } \\
\text { (Blong, 1984; Alexander, 1993). }\end{array}$ & $\begin{array}{l}\text { The buoyancy of the magma, the pressure from the exsolved } \\
\text { gases in the magma, and the injection of a new } \\
\text { batch of magma into an already filled magma chamber } \\
\text { (Kilinc, 1999). }\end{array}$ \\
\hline \multirow[t]{2}{*}{$\begin{array}{l}\text { Tropical } \\
\text { cyclone } \\
\text { (hurricane, } \\
\text { tropical storm, } \\
\text { typhoon) }\end{array}$} & \multirow[t]{2}{*}{$\begin{array}{l}\text { Storms with swirling atmospheric } \\
\text { disturbance occurring in tropical } \\
\text { or subtropical maritime regions } \\
\text { (McGuire et al., 2002; IFRC, 2013). }\end{array}$} & $\begin{array}{l}\text { Point of origin: (1) five degrees of } \\
\text { latitude away from the Equator; } \\
\text { (2) vast and warm ocean (Gray, 1979; } \\
\text { Henderson-Sellers et al., 1998; } \\
\text { McGuire et al., 2002). }\end{array}$ & $\begin{array}{l}\text { Point of origin: (1) water temperature at least } \\
26.5^{\circ} \mathrm{C} \text { down to a depth of at least } 50 \mathrm{~m} \text {; } \\
\text { (2) low amounts of weak vertical wind shear; } \\
\text { (3) a pre-existing system of disturbed weather; } \\
\text { and (4) high humidity (Gray, 1979; } \\
\text { Henderson-Sellers et al., 1998; } \\
\text { McGuire et al., 2002). }\end{array}$ \\
\hline & & $\begin{array}{l}\text { Track: the distance to the origin } \\
\text { (Smith, 2013). }\end{array}$ & $\begin{array}{l}\text { Track: the movement of tropical cyclones is accompanied } \\
\text { by strong winds and heavy rain, and a series of hazards } \\
\text { induced by the changes of winds and rainfall are the reasons } \\
\text { that damage occurs in the cyclone track (Smith, 2013). } \\
\text { Thus, tropical cyclone is viewed as the changes of wind speed } \\
\text { and rainfall, and these changes can be used as trigger factors } \\
\text { to measure the magnitude of other hazards in the track. }\end{array}$ \\
\hline $\begin{array}{l}\text { Slow riverine } \\
\text { flood }\end{array}$ & $\begin{array}{l}\text { Slow riverine flood occurs in relatively } \\
\text { flat areas, and land may stay covered } \\
\text { with shallow, slow-moving floodwater } \\
\text { for days or weeks (Kron, 2005). }\end{array}$ & $\begin{array}{l}\text { (1) Flat and low-lying terrain; } \\
\text { (2) river basins; and (3) land } \\
\text { surface with poor water infiltration } \\
\text { capacity (Kron, 2005). }\end{array}$ & $\begin{array}{l}\text { The most common is heavy rainfall. } \\
\text { Other factors include melting snow and ice, } \\
\text { and high tides (Barredo, 2007). }\end{array}$ \\
\hline $\begin{array}{l}\text { Fast } \\
\text { riverine } \\
\text { flood }\end{array}$ & $\begin{array}{l}\text { Fast riverine flood occurs in hilly } \\
\text { and mountainous areas, and are } \\
\text { characterized by a rapid rise in water, } \\
\text { with high velocities that occur in } \\
\text { an existing river channel over } \\
\text { a short period (Alexander, 1993). }\end{array}$ & $\begin{array}{l}\text { (1) Hilly or mountainous terrain; } \\
\text { (2) river basins; and (3) land } \\
\text { surface with poor water } \\
\text { infiltration capacity } \\
\text { (Alexander, 1993; Kron, 2005). }\end{array}$ & $\begin{array}{l}\text { The most common is heavy rainfall. } \\
\text { Other factors include melting snow and ice, } \\
\text { and high tides (Barredo, 2007). }\end{array}$ \\
\hline $\begin{array}{l}\text { Coastal } \\
\text { flood }\end{array}$ & $\begin{array}{l}\text { A normally dry coastal area } \\
\text { is inundated by sea water } \\
\text { (McGuire et al., 2002). }\end{array}$ & $\begin{array}{l}\text { (1) Flat and low-lying terrain; } \\
\text { (2) coastal area; and ( } 3 \text { ) land } \\
\text { surface with poor water } \\
\text { infiltration capacity } \\
\text { (McGuire et al., 2002; Barredo, 2007). }\end{array}$ & $\begin{array}{l}\text { Coastal flood can be induced by several } \\
\text { trigger factors including storm surges } \\
\text { induced by tropical cyclones, tidal waves } \\
\text { and tsunamis (McGuire et al., 2002; } \\
\text { Barredo, 2007). }\end{array}$ \\
\hline $\begin{array}{l}\text { Pluvial } \\
\text { flood }\end{array}$ & $\begin{array}{l}\text { The phenomenon where surface } \\
\text { water accumulates as input } \\
\text { exceeds infiltration. } \\
\text { It is common in low-lying } \\
\text { areas with poor water absorption } \\
\text { ability (Falconer et al., 2009; } \\
\text { Zhou et al., 2012). }\end{array}$ & $\begin{array}{l}\text { (1) Flat and low-lying terrain; } \\
\text { and (2) land surface with } \\
\text { poor water infiltration } \\
\text { capacity (a common attribute } \\
\text { of urban areas) } \\
\text { (Falconer et al., 2009; } \\
\text { Zhou et al., 2012). }\end{array}$ & $\begin{array}{l}\text { The principal trigger factor for } \\
\text { pluvial flood is heavy rainfall } \\
\text { (Maksimović et al., 2009). }\end{array}$ \\
\hline Landslide & $\begin{array}{l}\text { A geological phenomenon which includes } \\
\text { a wide range of ground movements with } \\
\text { rock and soil over a sloping surface } \\
\text { (Varnes, 1958). }\end{array}$ & $\begin{array}{l}\text { (1) Hilly or mountainous terrain; and } \\
\text { (2) slope material with poor water } \\
\text { absorption capacity (Varnes, 1984; } \\
\text { Guzzetti et al., 1999). }\end{array}$ & $\begin{array}{l}\text { (1) Heavy rainfall which increases the pressure } \\
\text { of material on the slope; and (2) earthquake which } \\
\text { reduces the resisting (shear) forces of the slope } \\
\text { (Varnes, 1984; Kuriakose et al., 2009). }\end{array}$ \\
\hline Avalanche & $\begin{array}{l}\text { A rapid flow of snow down } \\
\text { a sloping surface } \\
\text { (McClung and Schaerer, 2006; } \\
\text { Smith, 2013). }\end{array}$ & $\begin{array}{l}\text { (1) Hilly or mountainous terrain; and } \\
\text { (2) Slope with snowpack } \\
\text { (McClung and Schaerer, 2006; } \\
\text { Smith, 2013). }\end{array}$ & $\begin{array}{l}\text { (1) Heavy snowfall or rainfall which increases } \\
\text { the pressure of snowpack on the slope; } \\
\text { (2) metamorphic changes in the snowpack such } \\
\text { as melting due to solar radiation; and } \\
\text { (3) earthquake which reduces the resisting (shear) } \\
\text { forces of the slope (McClung and Schaerer, 2006; } \\
\text { Smith, 2013). }\end{array}$ \\
\hline Drought & $\begin{array}{l}\text { A condition of abnormal weather } \\
\text { resulting in a shortage of water } \\
\text { (Dracup et al., 1980; } \\
\text { Wilhite and Glantz, 1985; } \\
\text { McKee et al., 1993). }\end{array}$ & $\begin{array}{l}\text { (1) Low annual average precipitation; } \\
\text { (2) high annual average temperature; } \\
\text { (3) low drainage density; and } \\
\text { (4) land surface with poor water } \\
\text { absorption capacity (Alexander, 1993; } \\
\text { Smith and Petley, 2009). }\end{array}$ & $\begin{array}{l}\text { Lack of rainfall } \\
\text { (Smith and Petley, 2009). }\end{array}$ \\
\hline
\end{tabular}


ral hazards can be expressed as

$S\left(H_{k}\right)=f\left(\mathrm{SF}_{1}, \mathrm{SF}_{2} \ldots \mathrm{SF}_{j}\right)(j=1,2 \ldots n)$.

Thus, the susceptibility of each assessment unit to each hazard can be calculated as

$S_{i}\left(H_{k}\right)=\sum_{j=1}^{n} w_{j} \operatorname{Nor}\left(\mathrm{SF}_{j}\right)_{i}$,

where, for any given assessment unit $i: S$ is susceptibility, $H$ is hazard, SF is stable factors, $S_{i}\left(H_{k}\right)$ is susceptibility to hazard $k$, given stable factors $\mathrm{SF}_{j}, \operatorname{Nor}\left(\mathrm{SF}_{j}\right)_{i}$ is the normalization of stable factor $j$ in assessment unit $i$, and $w_{j}$ is the weight for stable factor $j$.

The $w_{j}$ can be calculated by one of several methods, including principal component analysis (PCA) (Cutter et al., 2000), analytic hierarchy method (AHP) (Thirumalaivasan et al., 2003) and fuzzy comprehensive evaluation (Dixon, 2005).

Having calculated the susceptibility of each assessment unit to each hazard, maps can be drawn to show the spatial distribution of individual hazards, then the spatial distribution of multiple hazards obtained through aggregation.

\subsection{Trigger factors for hazard analysis}

Substantial changes in trigger factors are the main reason that hazards are induced, thus trigger factors can be used to estimate both the frequency and magnitude of hazards. The degree of change in trigger factors represents hazard magnitude, and the probability of change in trigger factors represents hazard probability. The relationship between trigger factors and natural hazards can thus be expressed as

$$
f\left(p_{t_{i}}\right)=p\left(h_{j}\right)
$$

where one trigger factor induces one hazard;

$$
f\left(p_{t_{i}}\right)=p\left(h_{1}, h_{2} \ldots h_{j}\right)
$$

where one trigger factor induces multiple hazards;

$$
f\left(p_{t_{1}}, p_{t_{2}} \ldots p_{t_{i}}\right)=p\left(h_{j}\right)
$$

where multiple trigger factors induce one hazard; and

$$
f\left(p_{t_{1}}, p_{t_{2}} \ldots p_{t_{i}}\right)=p\left(h_{1}, h_{2} \ldots h_{j}\right)
$$

where multiple trigger factors induce multiple hazards. In these cases, $p\left(h_{j}\right)$ is the probability of hazard $j$, and $p_{t_{i}}$ is the probability of the change in trigger factor $i$.

The $p_{t_{i}}$ can be calculated by the mathematical statistics approach to define a function to determine event magnitude and frequency. For example, Grünthal et al. (2006) calculated exceedance probability vs. mean wind speed curves for windstorm magnitude assessment using Schmidt and Gumbel distributions (Gumbel, 1958).

\subsection{A systematic classification of hazard interactions}

Hazard interaction analysis is used to calculate the probability and magnitude of multiple hazards occurring together, given different types of possible relationships. According to the trigger factors for each hazard, the relationships between different natural hazards are categorized into four types.

\subsubsection{Independent relationship}

In the independent relationship, the changes in trigger factors which induce hazard $A$ are independent of that which induce hazard $\mathrm{B}$. The occurrences of these two hazards are independent, e.g. the trigger factors for typhoon and earthquake are unrelated.

The relationship between these trigger factors and hazards can be expressed as

$$
\begin{aligned}
& f\left(p_{t_{1}}, p_{t_{2}} \ldots p_{t_{i}}\right)=p\left(h_{\mathrm{A}}\right), \\
& f\left(p_{t_{i+1}}, p_{t_{i+2}} \ldots p_{t_{n}}\right)=p\left(h_{\mathrm{B}}\right),
\end{aligned}
$$

where $p_{t_{i}}$ is the probability of the change in trigger factor $i$, and $p\left(h_{j}\right)$ is the probability of hazard $j$ occurrence.

The changes in trigger factors $t_{1}, t_{2} \ldots t_{i}$ are independent of changes in trigger factors $t_{i+1}, t_{i+2} \ldots t_{n}$. If the changes in these trigger factors occur together, then hazards $\mathrm{A}$ and $\mathrm{B}$ happen together. Hence, the probability of these two hazards occurring together can be calculated as

$$
\begin{aligned}
P(\mathrm{~A} \bigcap \mathrm{B}) & =p\left(h_{\mathrm{A}}\right) \times p\left(h_{\mathrm{B}}\right)=f\left(p_{t_{1}}, p_{t_{2}} \ldots p_{t_{i}}\right) \\
& \times f\left(p_{t_{i+1}}, p_{t_{i+2}} \ldots p_{t_{n}}\right)
\end{aligned}
$$

where $p_{t_{i}}$ is the probability of the change in trigger factor $i$, and $p\left(h_{j}\right)$ is the probability of hazard $j$ occurrence.

\subsubsection{Mutex relationship}

Here, the changes in trigger factors which induce hazard A and which induce hazard B are mutually exclusive (mutex). Thus hazards A and B cannot occur together. The changes in trigger factors for these hazards can be expressed as

$$
\begin{aligned}
& f\left(p_{t_{i}+}\right)=p\left(h_{\mathrm{A}}\right), \\
& f\left(p_{t_{i}-}\right)=p\left(h_{\mathrm{B}}\right),
\end{aligned}
$$

where $t_{i}+$ represents the trigger factor $i$ departure in a positive direction from its mean value, $t_{i}$ - represents the trigger factor $i$ departure in a negative direction from its mean value, $p_{t_{i}}$ is the probability of the change in trigger factor $i$, and $p\left(h_{j}\right)$ is the probability of hazard $j$ occurrence.

One trigger factor cannot move in two directions simultaneously, hence, the probability of these two hazards occurring together can be expressed as

$$
P(\mathrm{~A} \bigcap \mathrm{B})=0
$$




\subsubsection{Parallel relationship}

The changes in one or some trigger factors have the chance to induce more than one hazard $\mathrm{A}_{1}, \mathrm{~A}_{2} \ldots \mathrm{A}_{n}$ at the same time. The relationship of hazards $A_{1}, A_{2} \ldots A_{n}$ is parallel. For example, fast riverine flood and landside induced by heavy rainfall can be taken as a parallel relationship. This relationship between trigger factors and these hazards can be expressed as

$f\left(p_{t_{1}}, p_{t_{2}} \ldots p_{t_{i}}\right)=p\left(h_{\mathrm{A}_{1}}\right)$,

$f\left(p_{t_{1}}, p_{t_{2}} \ldots p_{t_{i}}\right)=p\left(h_{\mathrm{A}_{2}}\right)$,

$f\left(p_{t_{1}}, p_{t_{2}} \ldots p_{t_{i}}\right)=p\left(h_{\mathrm{A}_{n}}\right)$,

where $p_{t_{i}}$ is the probability of the change in trigger factor $i$, and $p\left(h_{j}\right)$ is the probability of hazard $j$ occurrence.

Hazards $\mathrm{A}_{1}, \mathrm{~A}_{2} \ldots \mathrm{A}_{n}$ constitute a hazard group, with all hazards in the group induced by the same trigger factor(s). Hence, the frequency and magnitude of this hazard group are determined by the changes in these trigger factors. The probability of this hazard group (hazards $A_{1}, A_{2} \ldots A_{n}$ ) occurring can be expressed as

$$
P\left(\mathrm{~A}_{1} \bigcap \mathrm{A}_{2} \ldots \bigcap \mathrm{A}_{n}\right)=f\left(p_{t_{1}}, p_{t_{2}} \ldots p_{t_{i}}\right)
$$

where $p_{t_{i}}$ is the probability of the change in trigger factor $i$, and $p\left(h_{j}\right)$ is the probability of hazard $j$ occurrence.

\subsubsection{Series relationship}

In the series relationship, hazard $\mathrm{A}$ induces changes in some trigger factors, and then the changes in these trigger factors induce hazard B. This can be expressed as

$f\left(p_{t_{1}}, p_{t_{2}} \ldots p_{t_{i}}\right)=p\left(h_{\mathrm{A}}\right) \rightarrow f\left(p_{t_{i+1}}, p_{t_{i+2}} \ldots p_{t_{n}}\right)=p\left(h_{\mathrm{B}}\right)$,

where, $p_{t_{i}}$ is the probability of the change of trigger factor $i$, and $p\left(h_{j}\right)$ is the probability of hazard $j$ occurrence.

The changes of trigger factors $t_{1}, t_{2} \ldots t_{i}$ induce the hazard $\mathrm{A}$, then hazard A causes the changes in trigger factors $t_{i+1}, t_{i+2} \ldots t_{n}$. The changes in trigger factors $t_{i+1}, t_{i+2} \ldots t_{n}$ induce hazard B. Hence, the probability of hazard A and B occurring together can be expressed as

$$
\begin{aligned}
P(\mathrm{~A} \bigcap \mathrm{B}) & =p\left(h_{\mathrm{A}}\right) \times p\left(h_{\mathrm{B}}\right)=f\left(p_{t_{1}}, p_{t_{2}} \ldots p_{t_{i}}\right) \\
& \times f\left(p_{t_{i+1}}, p_{t_{i+2}} \ldots p_{t_{n}} \mid h_{\mathrm{A}}\right)=f\left(p_{t_{1}}, p_{t_{2}} \ldots p_{t_{i}}\right) \\
& \times f\left(p_{t_{i+1}}, p_{t_{i+2}} \ldots p_{t_{n}} \mid p_{t_{1}}, p_{t_{2}} \ldots p_{t_{i}}\right)
\end{aligned}
$$

where $p_{t_{i}}$ is the probability of the change of trigger factor $i$, $p\left(h_{j}\right)$ is the probability of hazard $j$, and $p_{t_{n}} \mid h_{\mathrm{A}}$ is the probability of the change of trigger factor $n$ given the magnitude of hazard A occurrence.

This classification is useful as it helps to ensure that all possible relationships among different hazards are considered. It can effectively fill a gap in current multi-hazard methods which to date only consider domino effects. In addition,

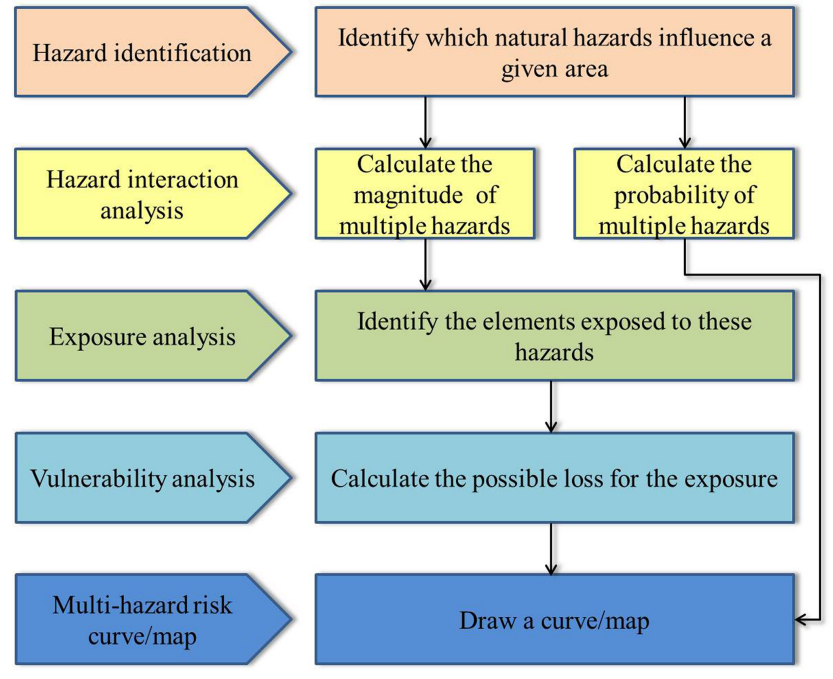

Figure 1. Basic framework of multi-hazard risk assessment.

the probability and magnitude of multiple hazards with these relationships occurring together also can be calculated based on substantial changes in trigger factors, with the change of degree in them representing the magnitude of hazards, and the probability of changes in them representing the probability of hazards. In the next section, this classification is applied within MHRA to demonstrate its utility.

\section{Application in multi-hazard risk assessment}

Generally, MHRA is based on single-hazard risk assessment. The main advance of MHRA is that it puts different types of hazards into a single system for joint evaluation (Armonia, 2006; Di Mauro et al., 2006; Marzocchi et al., 2009; Carpignano et al., 2009). The aim of MHRA is to have a holistic view of the total effects or impacts by assessing and mapping expected loss, due to the occurrence of various natural hazards, in the social, environmental and economic assets of a given area. In principle, it takes into account the characteristics of each hazardous event (probability, frequency, magnitude), and their mutual interactions and interrelations (e.g. one hazard may occur repeatedly in time; different hazards may occur independently in the same place; different hazards may occur dependently in the same place) (Kappes et al., 2012; Marzocchi et al., 2012). Figure 1 lists a basic framework of MHRA (Bell and Glade, 2004; Di Mauro et al., 2006; Marzocchi et al., 2009; Carpignano et al., 2009; Schmidt et al., 2011). There are five main components: (1) hazard identification: identify which natural hazards influence a given area; (2) hazard interaction analysis: calculate the probability and magnitude of multiple hazards occurring together; (3) exposure analysis: identify the elements exposed to these hazards; (4) vulnerability analysis: calculate the possible loss for the exposure, under con- 


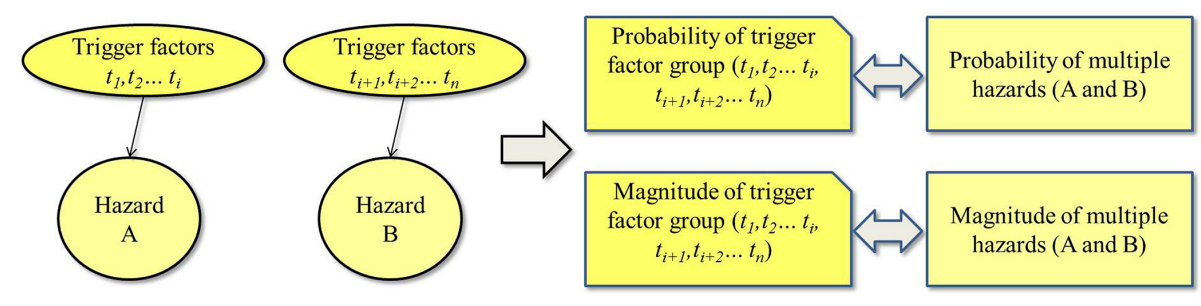

(a) Independent relationship

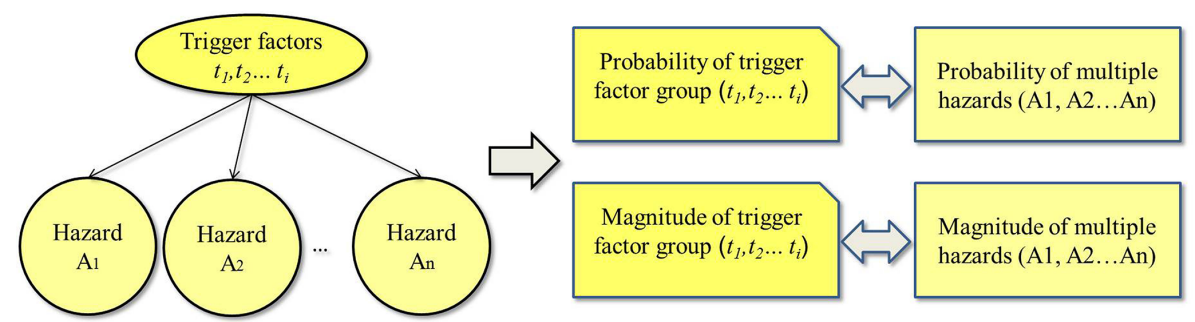

(b) Parallel relationship

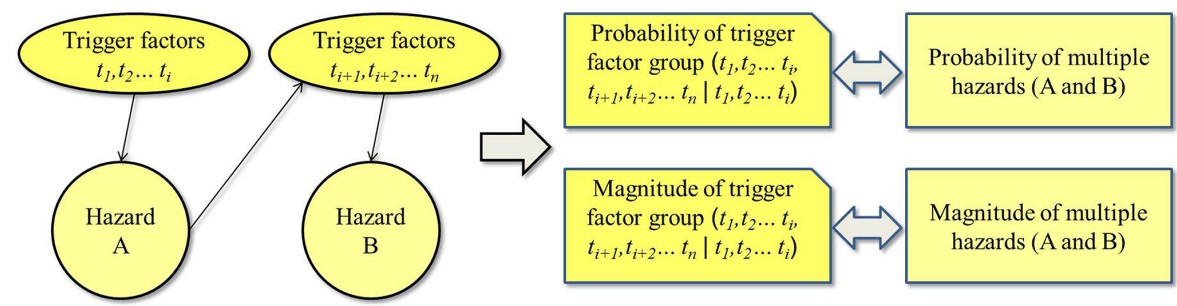

(c) Series relationship

Figure 2. Hazard interaction analysis for hazards with different relationships. (a) Independent relationship. (b) Parallel relationship. (c) Series relationship.

ditions caused by multiples hazards of varying magnitude; and (5) multi-hazard risk curve/map: draw a curve/map based on the probability of multiple hazards and the corresponding loss.

Magnitude refers to the strength or force of the hazard event, with magnitude measured using different units, depending on the hazard. This make it is hard to directly compare the magnitude of different hazards, therefore, in vulnerability analysis, most MHRA approaches calculate the loss in each hazard individually, with the same vulnerability, and these losses are summed to obtain the total loss. However, in reality, vulnerability may vary according to prior events. Hence, the final results obtained in these approaches cannot reflect the real loss situation.

In the proposed classification scheme, four types of interaction are identified: independent, mutex, parallel and series relationships. All possible hazard interactions can be considered in this classification scheme, and the frequency and magnitude of these multiple interacting hazards occurring together can be measured using the relevant trigger factors (Fig. 2). (Mutex is not shown, as by definition, these hazards cannot occur together.)

In Fig. 2a, hazards $\mathrm{A}$ and $\mathrm{B}$ are an independent relationship. The changes in trigger factors $t_{1}, t_{2} \ldots t_{i}$ which induce hazard $\mathrm{A}$ are independent of the changes in trigger factors $t_{i+1}, t_{i+2} \ldots t_{n}$ which induce hazard $\mathrm{B}$. These trigger factors can be taken as a trigger factor group $\left(t_{1}, t_{2} \ldots t_{i}, t_{i+1}, t_{i+2} \ldots t_{n}\right)$ to measure the frequency and magnitude of hazard $\mathrm{A}$ and $\mathrm{B}$ occurring together.

In Fig. $2 b$, hazards $A_{1}, A_{2} \ldots A_{n}$ represent a parallel relationship. Hazards $\mathrm{A}_{1}, \mathrm{~A}_{2} \ldots \mathrm{A}_{n}$ are all induced by the changes in the same trigger factors $t_{1}, t_{2} \ldots t_{i}$. The frequency and magnitude of this hazard group $\left(\mathrm{A}_{1}, \mathrm{~A}_{2} \ldots \mathrm{A}_{n}\right)$ are determined by the changes in these trigger factors. Hence, the trigger factor group $\left(t_{1}, t_{2} \ldots t_{i}\right)$ is chosen to measure the frequency and magnitude of hazard group $\left(A_{1}, A_{2} \ldots A_{n}\right)$.

In Fig. 2c, hazards $A$ and $B$ represent the series relationship. The changes in trigger factors $t_{1}, t_{2} \ldots t_{i}$ induce hazard $\mathrm{A}$, then the hazard $\mathrm{A}$ induces the changes in trigger factors $t_{i+1}, t_{i+2} \ldots t_{n}$. The changes in trigger factors $t_{i+1}, t_{i+2} \ldots t_{n}$ induce hazard $\mathrm{B}$. Here, the trigger factor group $\left(t_{1}, t_{2} \ldots t_{i}\right)$ is chosen to represent the magnitude of hazard $\mathrm{A}$, and the trigger factor group $\left(t_{i+1}, t_{i+2} \ldots t_{n}\right)$ is chosen to represent the magnitude of hazard $\mathrm{B}$. The probability and degree of the changes in the trigger factor group $\left(t_{i+1}, t_{i+2} \ldots t_{n}\right)$ are determined by the magnitude of hazard $\mathrm{A}$, that is, the changes in the trigger factor group $\left(t_{1}, t_{2} \ldots t_{i}\right)$. Hence, these two trigger factor groups combine in a new trigger fac- 
tor group $\left(t_{1}, t_{2} \ldots t_{i}, t_{i+1}, t_{i+2} \ldots t_{n} \mid t_{1}, t_{2} \ldots t_{i}\right)$ to measure the frequency and magnitude of hazards $\mathrm{A}$ and $\mathrm{B}$ occurring together.

As shown in Fig. 2, the frequency and magnitude of multiple hazards occurring together can be measured by the relevant trigger factor group in the hazard interaction analysis. Therefore, in vulnerability analysis, the multiple interacting hazards can be treated as a multiple hazards group with the change of degree in the relevant trigger factor group representing the magnitude, and the relevant vulnerability corresponding to this whole group rather than the component single hazards. In this way, the results obtained are more reliable. In the next section, we apply this classification scheme within a MHRA model to estimate potential loss caused by multiple hazards in China's Yangtze River Delta (YRD).

\section{A case study in China's Yangtze River Delta}

\subsection{Hazard identification}

The YRD, facing the Pacific to the east, is a major floodplain characterized by low, flat terrain and numerous rivers, lakes and canals. It is highly prone to a range of natural hazards. Due to the abundant rainfall and high channel density, the whole YRD is liable to frequent riverine floods. The YRD is coastal and an oceanic landform between Eurasia and the $\mathrm{Pa}$ cific, so the coastal areas are also susceptible to typhoons and coastal floods. The northern plain areas, below an average altitude of $200 \mathrm{~m}$, are vulnerable to pluvial floods, whilst the southern hilly areas are subject to landslides and fast riverine floods. The YRD is located in a relatively stable geological platform, so highly destructive earthquakes (over magnitude 6) are unlikely. Given these characteristics, our case study focuses on typhoon, flood (slow riverine flood, fast riverine flood, coastal flood and pluvial flood) and landslide.

Given the stable factors shown in Table 1, the susceptibility of each county (the geographical unit of analysis within the YRD) to each hazard can be calculated based on Eq. (2). According to the types of hazards in each county, the whole YRD area is divided into four zones (Fig. 3). Counties in zone I are susceptible to three kinds of hazards: typhoon, slow riverine flood and pluvial flood. Counties in zone II are susceptible to four kinds of hazards, typhoon, slow riverine flood, pluvial flood and coastal flood. Counties in zone III are susceptible to five kinds of hazards, typhoon, slow riverine flood, fast riverine flood, pluvial flood and landslide. Counties in zone IV are susceptible to all six natural hazards (as zone III plus coastal flood), typhoon, slow riverine flood, fast riverine flood, pluvial flood, coastal flood and landslide. This regionalization is helpful in identifying the multi-hazard situation in each county, and thus is the basis for hazard interaction analysis.

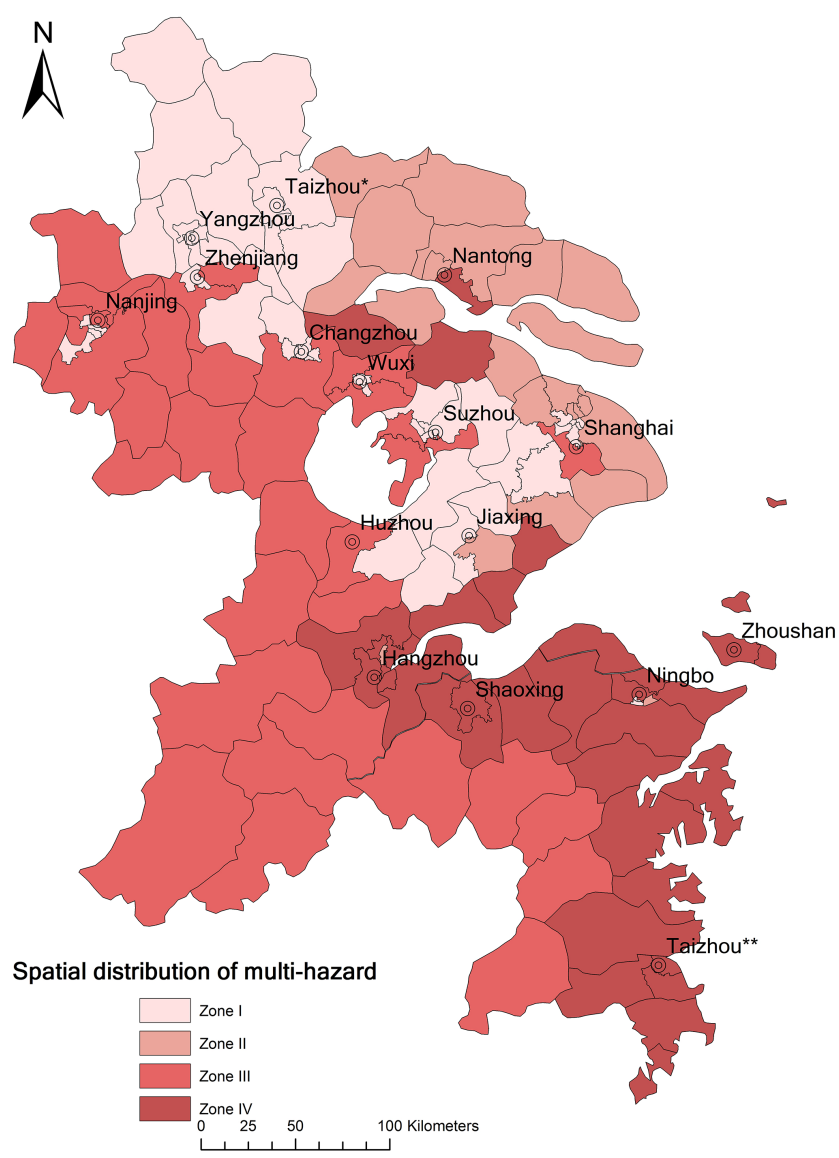

Figure 3. Spatial distribution of multi-hazard in the Yangtze River Delta. (Note that Taizhou* is in Jiangsu Province and Taizhou** is in Zhejiang Province.) Zone I: typhoon, slow riverine flood, pluvial flood. Zone II: typhoon, slow riverine flood, pluvial flood and coastal flood. Zone III: typhoon, slow riverine flood, fast riverine flood, pluvial flood and landslide. Zone IV: typhoon, slow riverine flood, fast riverine flood, pluvial flood, coastal flood and landslide.

\subsection{Hazard interaction analysis}

Hazard interaction is analysed for each of these four zones. According to the trigger factors for YRD hazards, the relationships among multiple hazards in the YRD can then be shown (Fig. 4). Take zone I: with typhoon-triggered rainfall as an example. Here, typhoon is viewed as the trigger factor, with changes of wind speed and rainfall, which induce slow riverine flood, pluvial flood and strong wind. These three hazards are in a parallel relationship and constitute a hazard group with each hazard induced by common trigger factors (wind speed and rainfall). Hence, the frequency and magnitude of this hazard group are determined by the changes in wind speed and rainfall. The exceedance probability of this hazard group (slow riverine flood, pluvial flood and strong wind) occurring with different magnitudes can be expressed 


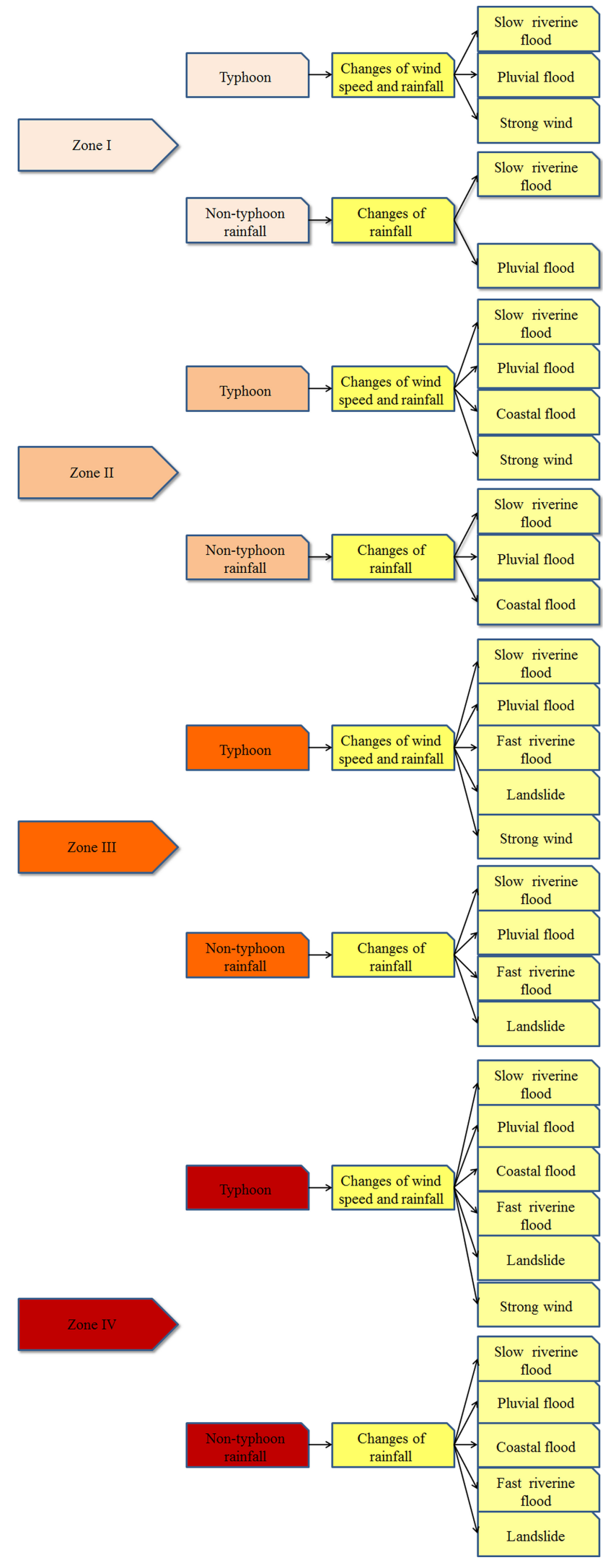

Figure 4. The relationships among multiple hazards in the Yangtze River Delta. as

$\mathrm{EP}\left(H_{\mathrm{s}} \cap H_{\mathrm{p}} \cap H_{\mathrm{w}}\right)=\mathrm{EP}($ wind speed, rainfall $)$,

where $H_{\mathrm{s}}$ is slow riverine flood, $H_{\mathrm{p}}$ is pluvial flood, $H_{\mathrm{w}}$ is strong wind and EP (wind speed, rainfall) is the exceedance probability of the corresponding maximum daily rainfall and maximum daily wind speed sets, which can be calculated based on the mathematical statistics approach with maximum daily rainfall and maximum wind speed during each historical typhoon.

In the same way, the exceedance probabilities of multiple hazards in other zones also can be calculated. Thus for:

- Zone I: trigger - non-typhoon rainfall,

$$
\operatorname{EP}\left(H_{\mathrm{s}} \cap H_{\mathrm{p}}\right)=\mathrm{EP}(\text { non-typhoon rainfall); }
$$

- Zone II: trigger - typhoon rainfall,

$$
\mathrm{EP}\left(H_{\mathrm{s}} \cap H_{\mathrm{p}} \cap H_{\mathrm{c}} \cap H_{\mathrm{w}}\right)=\mathrm{EP}(\text { wind speed, rainfall); }
$$

- Zone II: non-typhoon rainfall as trigger factor,

$$
\operatorname{EP}\left(H_{\mathrm{s}} \cap H_{\mathrm{p}} \cap H_{\mathrm{c}}\right)=\mathrm{EP}(\text { non-typhoon rainfall }) ;
$$

- Zone III: trigger - typhoon rainfall,

$$
\mathrm{EP}\left(H_{\mathrm{S}} \cap H_{\mathrm{p}} \cap H_{\mathrm{f}} \cap H_{1} \cap H_{\mathrm{w}}\right)=\mathrm{EP}(\text { wind speed, rainfall); }
$$

- Zone III: trigger - non-typhoon rainfall,

$$
\mathrm{EP}\left(H_{\mathrm{s}} \cap H_{\mathrm{p}} \cap H_{\mathrm{f}} \cap H_{1}\right)=\mathrm{EP}(\text { non-typhoon rainfall }) ;
$$

- Zone IV: trigger - typhoon rainfall,

$$
\begin{gathered}
\mathrm{EP}\left(H_{\mathrm{s}} \cap H_{\mathrm{p}} \cap H_{\mathrm{c}} \cap H_{\mathrm{f}} \cap H_{\mathrm{l}} \cap H_{\mathrm{w}}\right) \\
\quad=\mathrm{EP} \text { (wind speed, rainfall); }
\end{gathered}
$$

- Zone IV: trigger - non-typhoon rainfall,

$$
\begin{aligned}
& \operatorname{EP}\left(H_{\mathrm{s}} \cap H_{\mathrm{p}} \cap H_{\mathrm{c}} \cap H_{\mathrm{f}} \cap H_{\mathrm{l}}\right) \\
& \quad=\mathrm{EP}(\text { non-typhoon rainfall); }
\end{aligned}
$$

where $H_{\mathrm{s}}$ is slow riverine flood, $H_{\mathrm{p}}$ is pluvial flood, $H_{\mathrm{w}}$ is strong wind, $H_{\mathrm{f}}$ is fast riverine flood, $H_{\mathrm{c}}$ is coastal flood, $H_{1}$ is landslide, EP(non-typhoon rainfall) is the exceedance probability of the corresponding maximum non-typhoon daily rainfall, which can be calculated based on the mathematical statistics approach with maximum daily rainfall during each historical non-typhoon rainfall, and EP(wind speed, rainfall) is the exceedance probability of the corresponding maximum daily rainfall and maximum daily wind speed sets, which can be calculated based on the mathematical statistics approach with maximum daily rainfall and maximum wind speed during each historical typhoon.

Taking typhoon as an example, the results, as distribution of maximum daily rainfall and maximum wind speed with different exceedance probabilities, are shown in Fig. 5. 


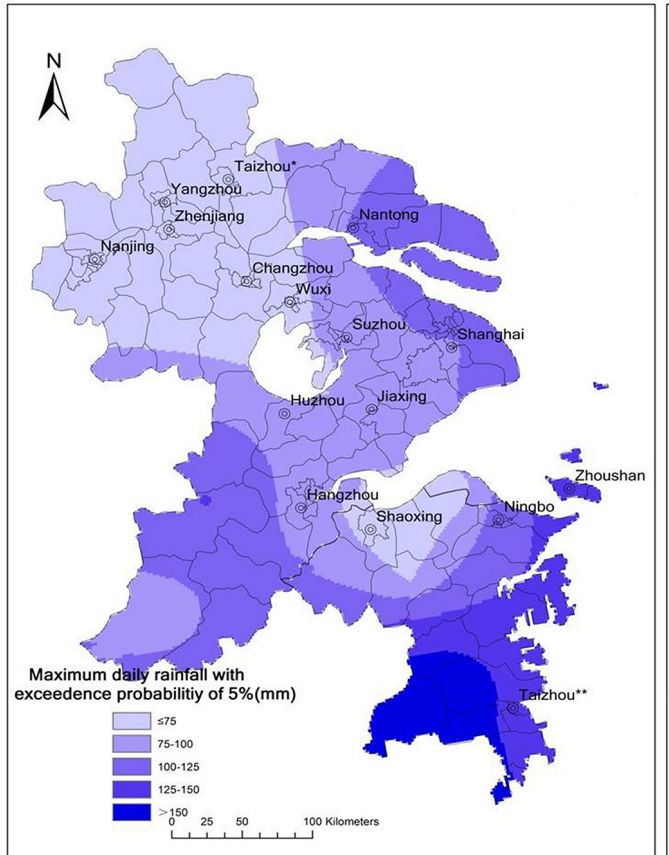

(a)

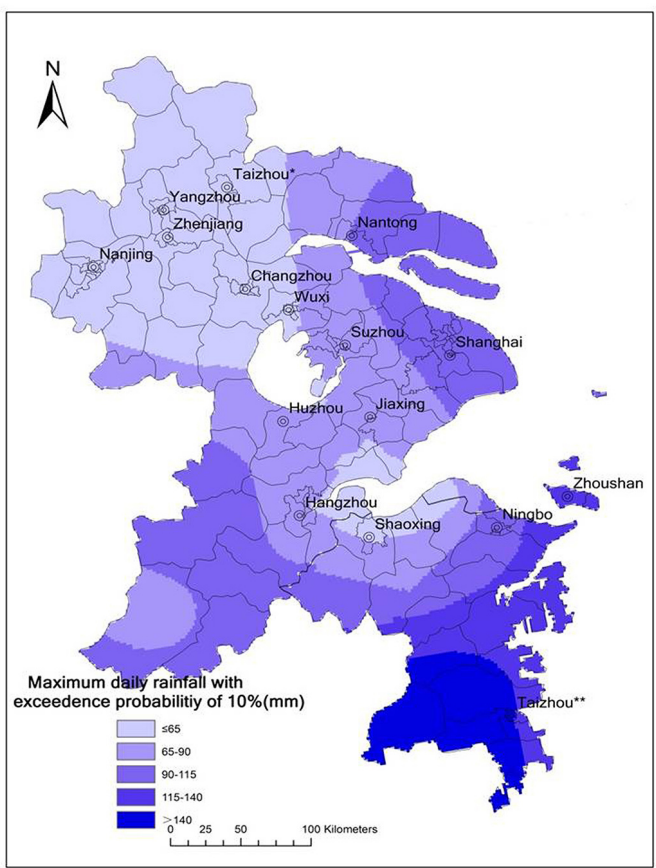

(c)

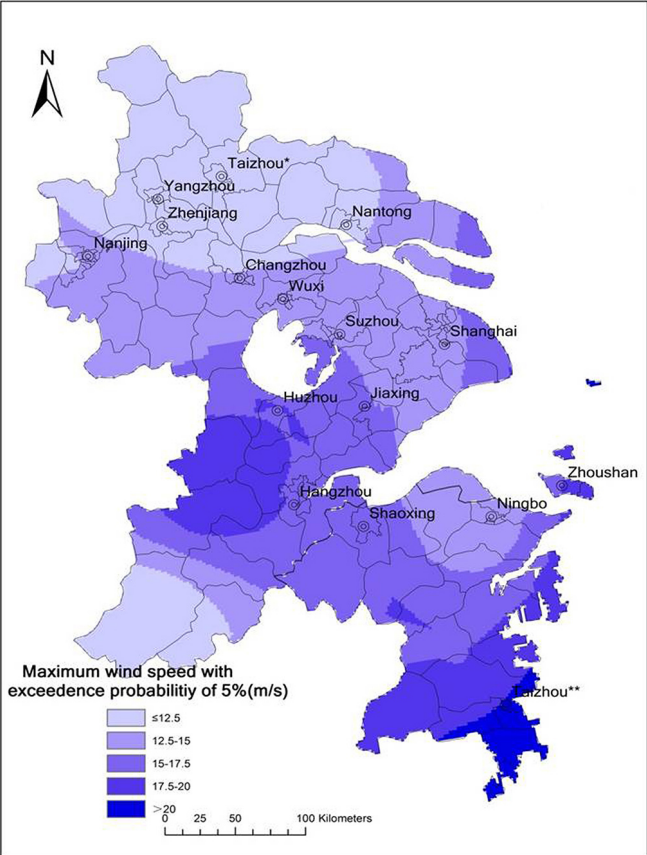

(b)

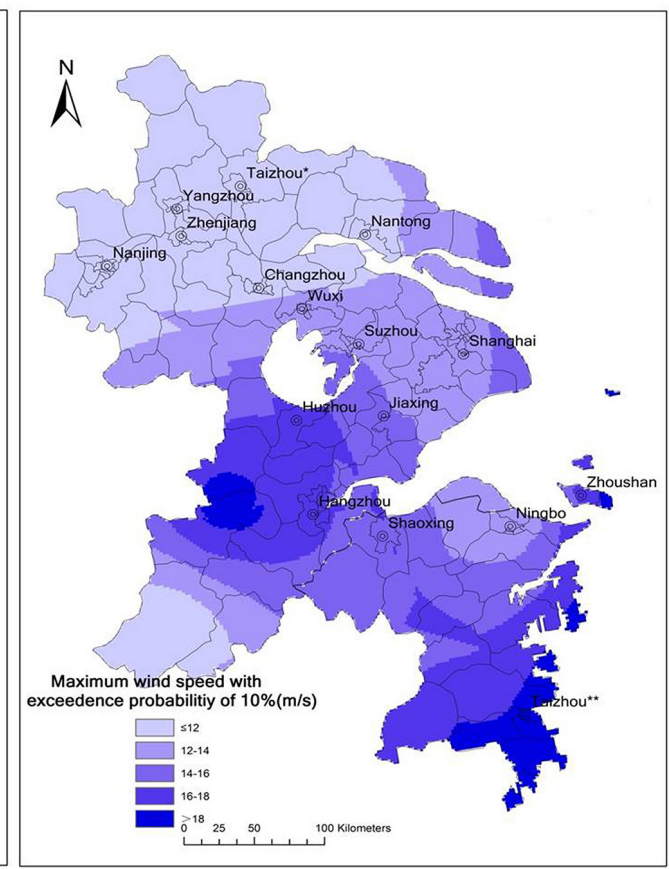

(d)

Figure 5. Distribution of maximum daily rainfall and maximum wind speed during typhoon with different exceedance probabilities. (a) Maximum daily rainfall distribution with exceedance probability of $5 \%$. (b) Maximum wind speed distribution with exceedance probability of $5 \%$. (c) Maximum daily rainfall distribution with exceedance probability of $10 \%$. (d) Maximum wind speed distribution with exceedance probability of $10 \%$.

\subsection{Multi-hazard risk assessment}

The hazard interaction analysis is then applied within the MHRA. Here, the YRD being struck by two consecutive typhoons (the most common multi-hazard scenario in the YRD) is taken as an example of this risk assessment. Maximum daily rainfall and maximum daily wind speed in each typhoon are selected as trigger factors to construct the set 


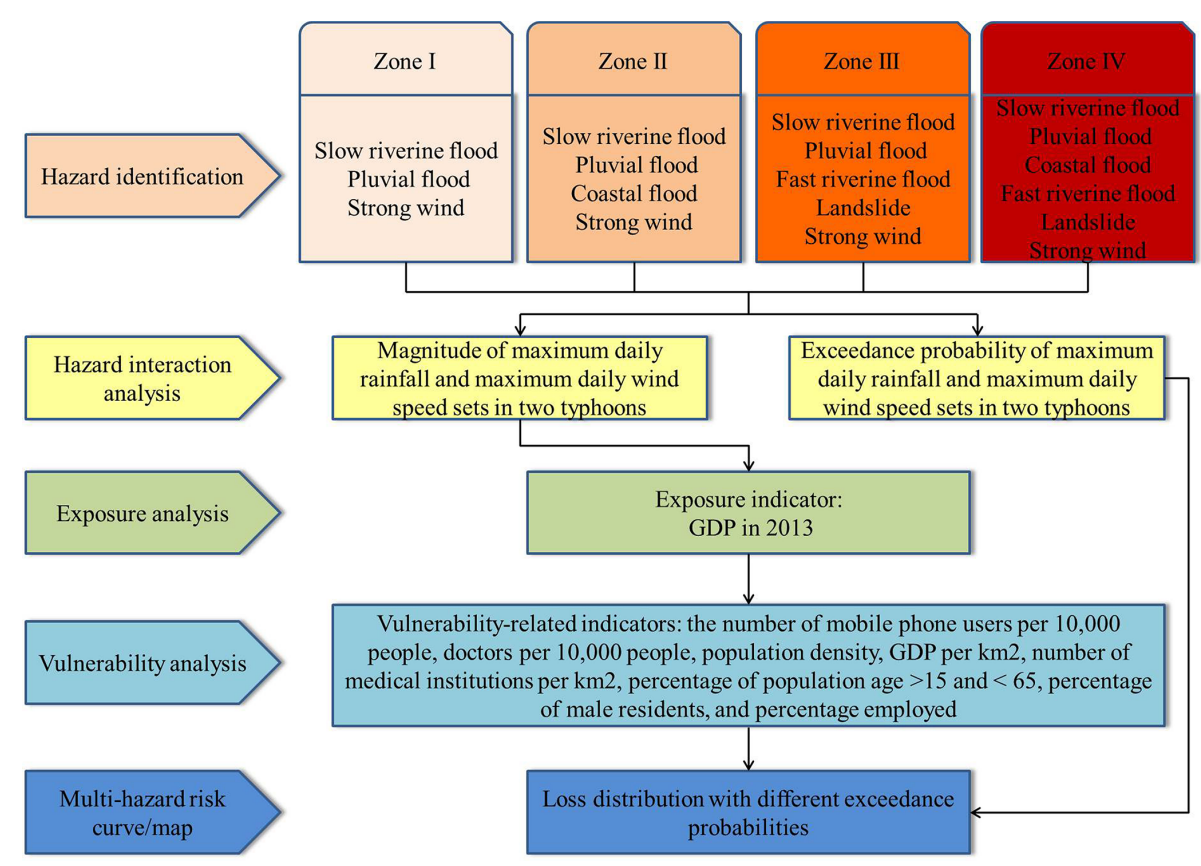

Figure 6. Basic framework of multi-hazard risk assessment for two consecutive typhoons in the Yangtze River Delta.

of hazard-related indicators which represent the magnitudes of multiple hazards. The first and second typhoons have an independent relationship, so based on the hazard interaction analysis in Sect. 5.2, the MHRA framework in the four zones of the YRD can be constructed as shown in Fig. 6.

With respect to losses, this case study takes the economic loss as an example, with GDP in 2013 selected as the exposure indicator. The vulnerability-related indicators selected were: the number of mobile phone users per 10000 people, doctors per 10000 people, population density, GDP per km², number of medical institutions per $\mathrm{km}^{2}$, percentage of population age $>15$ and $<65$, percentage of male residents, and percentage employed (Cutter et al., 2000; Liu, 2015). Based on the historical loss data from 1980 to 2012, the loss distribution influenced by typhoons with different exceedance probabilities is then calculated, with results shown in Fig. 7.

\section{Discussion}

\subsection{Contribution to multi-hazard risk assessment}

In this research, a comprehensive approach to classify hazard interactions based on analysis of the hazard-forming environment has been developed. The proposed hazard interaction classification provides a useful tool to facilitate improved MHRA. We now discuss the importance of such hazardforming environment analysis within the wider MHRA process.
For hazard identification, historical data analysis is a commonly used method (Munich Re, 2003; UNDP, 2004). However, this method relies on extensive historical data (at least 20 years) which is often unavailable for some areas. Additionally, because hazard occurrence is a random event, historical data may not contain all the possible hazard situations, especially as some hazards have a long return period (e.g. volcanic eruption). In this research, analysis of stable factors is used, identifying hazard from environmental factors rather than past observations of hazard, and so all possible hazard situations can be considered, even if some hazards have long return periods. Thus, stable factor analysis helps to fill a significant gap in existing hazard identification as hazard records may not reflect all possible hazard situations due to their long return period. In addition, compared to historical hazard data, most data for stable factors are easy to collect, e.g. river basins, landform. Hence, stable factors for hazard identification also can be used to solve the data problems of existing methods.

In hazard interaction, relationships among hazards were systematized for the first time in the MHRA research field, based on trigger factor analysis. A four-class hazard interaction categorization was developed: independent, mutex, parallel and series relationships. The application of this categorization ensures that all possible relationships among different hazards are considered in the MHRA. Thus, trigger factor analysis can effectively fill the gap in existing methods which to date only consider domino effects.

With respect to vulnerability analysis, we know that some hazards may hit a given area consecutively over a short pe- 


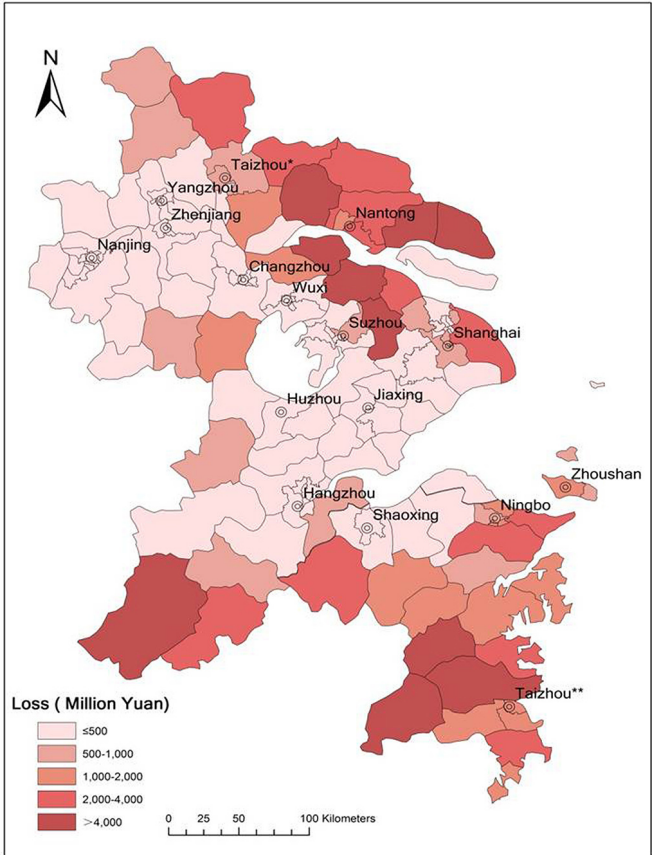

(a)

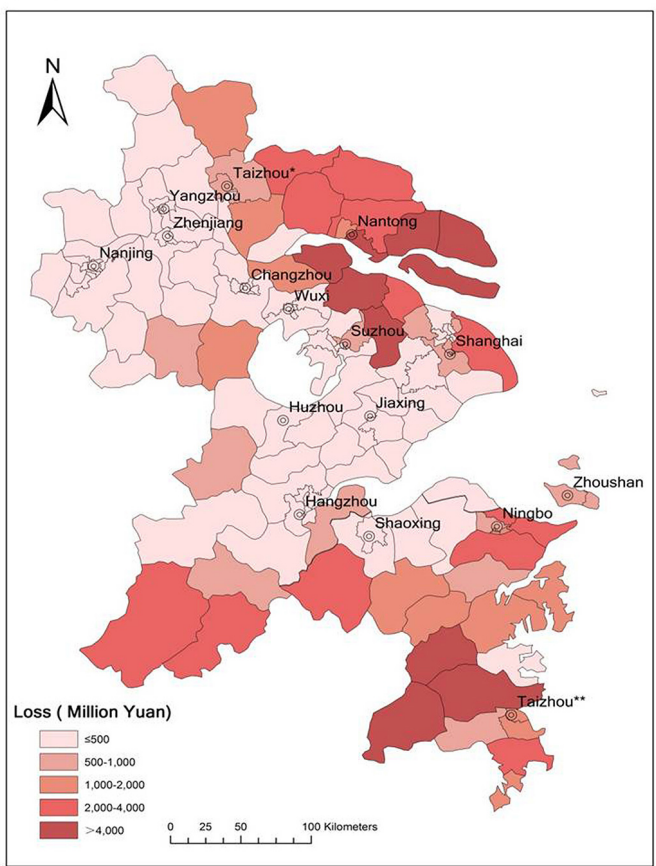

(c)

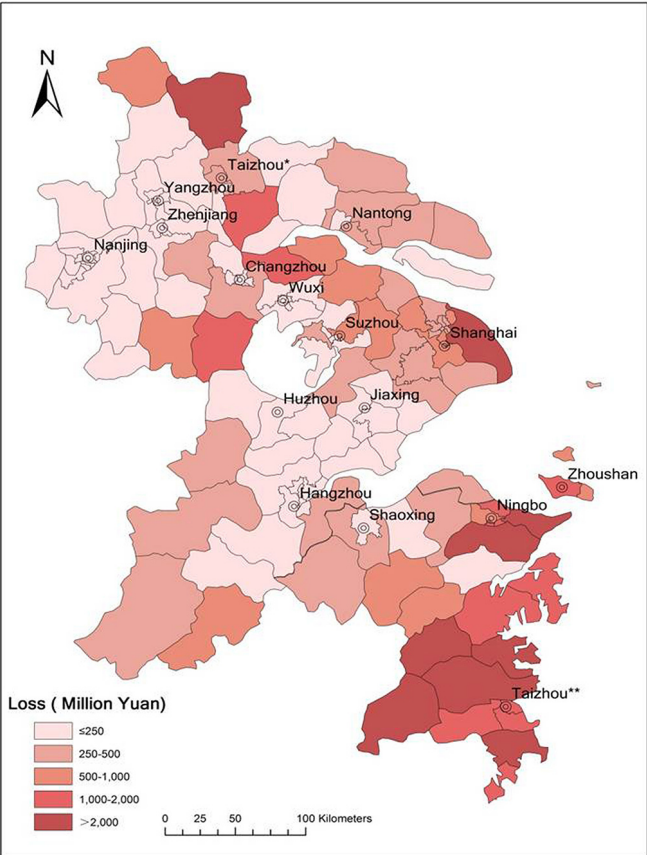

(b)

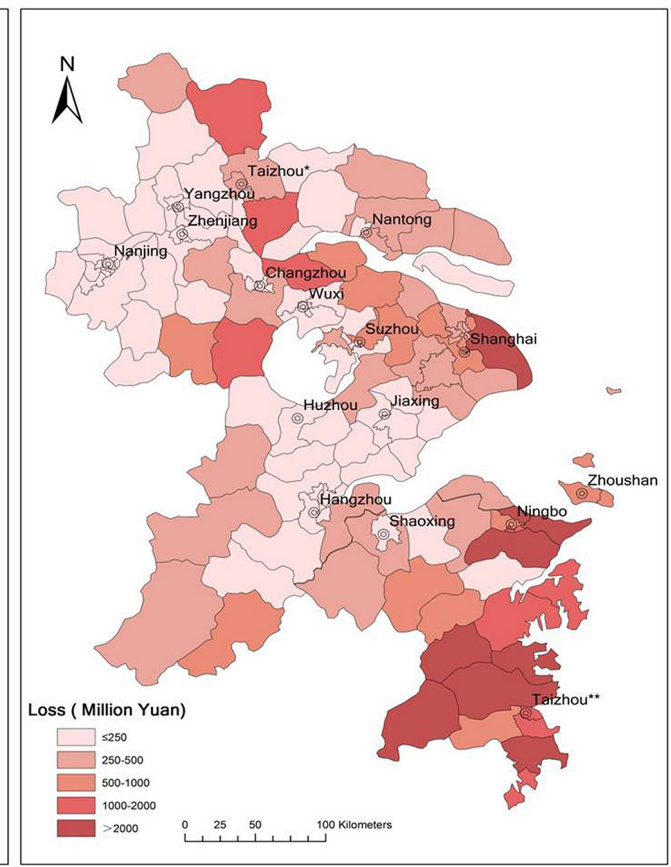

(d)

Figure 7. Loss distribution influenced by two consecutive typhoons with different exceedance probabilities. (a) Loss distribution influenced by two typhoons with exceedance probability of $1 \%$ and exceedance probability of $10 \%$. (b) Loss distribution influenced by two typhoons with exceedance probability of $5 \%$ and exceedance probability of $10 \%$ (c) Loss distribution influenced by two typhoons with exceedance probability of $10 \%$ and exceedance probability of $1 \%$. (d) Loss distribution influenced by two typhoons with exceedance probability of $10 \%$ and exceedance probability of $5 \%$.

riod. A short interval between such hazards means that recovery is constrained, and hence that vulnerability is not constant for each new event. However, existing MHRA methods calculate loss for each hazard individually, assuming equal vulnerability, before then summing to obtain the final loss. Thus, the final results cannot reflect the real loss situation, 
where vulnerability varies according to prior events. With our approach, the frequency and magnitude of hazards occurring together can be calculated by trigger factors in the hazard interaction analysis. Therefore, in the vulnerability analysis, hazards can be treated as a multiple hazards group, with the relevant vulnerability corresponding to this group rather than the component single hazards. In this way, the results obtained are more reliable.

\subsection{Limitations in hazard-forming environment analysis}

Hazard-forming environment analysis provides a useful tool for MHRA. However, as the formation of some hazards is not fully understood, there are some limitations to hazardforming environment analysis.

Firstly, according to the contribution to natural hazard, environmental factors in hazard-forming environment were categorized into two types. Factors in the first type are stable factors which form the background to the occurrence of natural hazards. These stable factors were used to identify which kinds of hazards could influence a given area and deduce the spatial distribution of these hazards. However, the occurrences of some natural hazards, such as thunderstorm or tornado, have no obvious environment characteristic. These hazards could probably happen anywhere, thus existing knowledge about the hazard-forming environment is insufficient to identify the spatial distribution of these hazards.

A second problem lies with the trigger factors. Substantial changes in trigger factors are the main reason that hazards are induced. According to the trigger factors for each hazard, the relationships between different natural hazards can be categorized, and the probability of these relationships occurring can be calculated. However, knowledge of trigger factors is incomplete, and there may still be some unknown trigger factors which could induce new relationships between natural hazards that we have not considered above.

\section{Conclusion}

This study has developed a systematic hazard interaction classification based on characteristics of the hazard-forming environment. According to the contribution to natural hazards, the geophysical environmental factors in the hazardforming environment were categorized into two types, stable factors and trigger factors. Based on these geophysical environmental factors for notable major hazards, the stable factors were used to identify which types of natural hazards influence a given area, and trigger factors are used to classify the relationships between these hazards into four types: independent, mutex, parallel and series relationships.

We applied this classification within MHRA. This classification is useful as it helps to ensure all possible relationships among different hazards are considered. It can effectively fill a gap in current MHRA methods which to date only consider domino effects. In addition, based on this classification, the frequency and magnitude of multiple interacting hazards occurring together can be calculated with the change in trigger factors. Therefore, in MHRA, these multiple interacting hazards can be treated as a multiple hazards group, with the change of degree in the relevant trigger factors representing the magnitude, and the probability of changes in them representing the probability of this group. In this way, the results obtained are more reliable. Hence, the developed hazard interaction classification based on hazard-forming environment provides a useful tool to facilitate improved MHRA.

MHRA is performed primarily for the purpose of providing information and insight to those who make decisions about how natural hazard risk should be managed. The hazard interaction classification developed in this research helps MHRA provide more reliable results, which can help public planners and decision-makers make optimal investment in disaster avoidance and mitigation. The classification also helps public planners and decision-makers understand the possible interactions among different hazards, so they can take appropriate and more targeted mitigation measures. Public planners and decision-makers can also use hazardforming environment analysis to help residents, businesses and other organizations to better understand the natural hazards they are exposed to, and their susceptibility to these hazards, thus enhancing public risk awareness and informing local risk management.

Acknowledgements. We are grateful to NHESS editor Thomas Glade for the editorial handling. We would like to thank Martin Mergili and one anonymous reviewer for their insightful comments and suggestions.

Edited by: T. Glade

Reviewed by: M. Mergili and one anonymous referee

\section{References}

Alexander, D.: Natural Disasters, UCL Press, London, 1993.

Armonia - Applied Multi-Risk Mapping of Natural Hazards for Impact Assessment: Applied Multi-Risk Mapping of Natural Hazards for Impact Assessment, Report on New Methodology for Multi-Risk Assessment and the Harmonisation of Different Natural Risk Maps, Armonia, European Community, Brussels, 85 pp., 2006.

Barredo, J. I.: Major Flood Disasters in Europe: 1950-2005, Nat. Hazards, 42, 125-148, 2007.

Bell, R. and Glade, T.: Quantitative risk analysis for landslides examples from Bíldudalur, NW-Iceland, Nat. Hazards Earth Syst. Sci., 4, 117-131, doi:10.5194/nhess-4-117-2004, 2004.

Blong, R. J.: Volcanic hazards: a sourcebook on the effects of eruptions, Academic Press, Sydney, 1984. 
Carpignano, A., Golia, E., Di Mauro, C., Bouchon, S., and Nordvik, J.: A methodological approach for the definition of multi-risk maps at regional level: first application, J. Risk Res., 12, 513534, 2009.

Cutter, S. L., Mitchell, J. T., and Scott, M. S.: Revealing vulnerability of people and place: a case study of Geogretown county, South Carolina, Ann. Assoc. Am. Geogr., 90, 713-737, 2000.

Di Mauro, C., Bouchon, S., Carpignana, A., Golia, E., and Peressin, S.: Definition of multi-risk maps at regional level as management tool: experience gained by civil protection authorities of Piemonte region, in: 5th Conference on Risk Assessment and Management in the Civil and Industrial Settlements, 17-19 October 2006, University of Pisa, Italy, 2006.

Dixon, B.: Groundwater vulnerability mapping: a GIS and fuzzy rule based integrated tool, Appl. Geogr., 25, 327-347, 2005.

Dracup, J. A., Lee, K. S., and Paulson, E. G.: On the definition of droughts, Water Resour. Res., 16, 297-302, 1980.

Eshrati, L., Mahmoudzadeh, A., and Taghvaei, M.: Multi hazards risk assessment, a new methodology, Int. J. Health Syst. Disaster Manage., 3, 79-88, 2015.

Falconer, R. H., Cobby, D., Smyth, P., Astle, G., Dent, J., and Golding, B.: Pluvial flooding: new approaches in flood warning, mapping and risk management, J. Flood Risk Manage., 2, 198-208, 2009.

Frolova, N. I., Larionov, V. I., Sushchev, S. P., and Bonnin, J.: Seismic and integrated risk assessment and management with information technology application, in: 15th World Conference on Earthquake Engineering, 24-28 September 2012, Lisbon, Portugal, 2012.

Garcia-Aristizabal, A. and Marzocchi, W.: Scenarios of Cascade Events, ENV.2010.6.1.3.4, New Methodologies for MultiHazard and Multi-Risk Assessment, European Commission, Brussels, 82 pp., 2013.

Gill, J. C. and Malamud, B. D.: Reviewing and visualizing the interactions of natural hazards, Rev. Geophys., 52, 680-722, 2014.

Gray, W. M.: Hurricanes: Their formation, structure and likely role in the tropical circulation, in: Meteorology Over Tropical Oceans edited by: Shaw, D. B., Roy. Meteor. Soc., James Glaisher House, Grenville Place, Bracknell, Berkshire, 77, 155-218, 1979.

Grünthal, G., Thieken, A. H., Schwarz, J., Radtke, K. S., Smolka, A., and Merz, B.: Comparative risk assessment for the city of Cologne-storms, floods, earthquake, Nat. Hazards, 38, 21-44, 2006.

Gumbel, E. J.: Statistics of Extremes, Columbia University Press, New York, 1958.

Guzzetti, F., Carrara, A., Cardinali, M., and Reichenbach, P.: Landslide hazard evaluation: a review of current techniques and their application in a multi-scale study, Central Italy, Geomorphology, 31, 181-216, 1999.

Henderson-Sellers, A., Zhang, H., Berz, G., Emanuel, K., Gray, W., Landsea, C., Holland, G., Lighthill, J., Shieh, S.-L., Webster, P., and McGuffie, K.: Tropical cyclones and global climate change: a post-IPCC assessment, B. Am. Meteorol. Soc., 79, 1938, 1998.

IFRC - International Federation of Red Cross and Red Crescent Societies: Meteorological Hazards: Tropical Storms, Hurricanes, Cyclones and Typhoons, available at: https://www.ifrc.org/en/what-we-do/ disaster-management/about-disasters/definition-of-hazard/ tropical-storms-hurricanes-typhoons-and-cyclones, last access: 1 October 2015, 2013.

Kappes, M. S., Keiler, M., and Glade, T.: From single- to multihazard risk analyses: a concept addressing emerging challenges, in: Mountain Risks: Bringing Science to Society, edited by: Malet, J. P., Glade, T., and Casagli, N., CERG Editions, Strasbourg, France, 351-356, 2010.

Kappes, M. S., Keiler, M., von Elverfeldt, K., and Glade, T.: Challenges of analyzing multi-hazard risk: a review, Nat. Hazards, 64, 1925-1958, 2012.

Kilinc, A.: What Causes a Volcano to Erupt and How Do Scientists Predict Eruptions, Scientific American, available at: http://www. scientificamerican.com/article/what-causes-a-volcano-to/, last access: 1 October 2015, 1999.

Kron, W.: Flood risk = hazard · values · vulnerability, Water Int., 30, 58-68, 2005.

Kuriakose, S. L., Sankar, G., and Muraleedharan, C.: History of landslide susceptibility and a chorology of landslide-prone areas in the Western Ghats of Kerala, India, Environ. Geol., 57, 1553-1568, 2009.

Liu, B.: Modelling multi-hazard risk assessment: a case study in the Yangtze River Delta, China, PhD thesis, School of Earth and Environment, The University of Leeds, Leeds, UK, 201 pp., 2015.

Maksimović, Č., Prodanović, D., Boonya-Aroonnet, S., Leitao, J. P., Djordjević, S., and Allitt, R.: Overland flow and pathway analysis for modelling of urban pluvial flooding, J. Hydraul. Res., 47, 512-523, 2009.

Marzocchi, W., Mastellone, M., Di Ruocco, A., Novelli, P., Romeo, E., and Gasparini, P.: Principles of Multi-Risk Assessment: Interactions Amongst Natural and Man-Induced Risks, European Commission, Directorate-General for Research, Environment Directorate, Luxembourg, 72 pp., 2009.

Marzocchi, W., Garcia-Aristizabal, A., Gasparini, P., Mastellone, M., and Di Ruocco, A.: Basic principles of multi-risk assessment: a case study in Italy, Nat. Hazards, 62, 551-573, 2012.

McClung, D. and Schaerer, P. A.: The Avalanche Handbook, The Mountaineers Books, Seattle, 2006.

McGuire, B., Mason, I., and Kilburn, C.: Natural Hazards and Environmental Change, Arnold, London, 2002.

McKee, T. B., Doesken, N. J., and Kleist, J.: The relationship of drought frequency and duration to time scales, in: 8th Conference on Applied Climatology, 17-22 January 1993, Anaheim, California, 1993.

Munich Re - Munich Reinsurance Company: Topics - Annual Review: Natural Catastrophes 2002, Munich Re Group, Munich, 2003.

Nishenko, S. P. and Buland, R.: A generic recurrence interval distribution for earthquake forecasting, B. Seismol. Soc. Am., 77, 1382-1399, 1987.

Pacheco, J. F., Sykes, L. R., and Scholz, C. H.: Nature of seismic coupling along simple plate boundaries of the subduction type, J. Geophys. Res., 98, 14133-14159, 1993.

Park, C.: Environment issues, Prog. Phys. Geogr., 18, 411-424, 1994.

Schmidt, J., Matcham, I., Reese, S., King, A., Bell, R., Henderson, R., Smart, G., Cousins, J., Smith, W., and Heron, D.: Quantitative multi-risk analysis for natural hazards: a framework for multirisk modelling, Nat. Hazards, 58, 1169-1192, 2011. 
Shi, P. J.: Theory and practice of disaster study, Journal of Natural Disasters, 5, 6-17, 1996.

Smith, K.: Environmental Hazards: Assessing Risk and Reducing Disaster, 6th Edn., Routledge, New York, 2013.

Smith, K. and Petley, D. N.: Environmental Hazards: Assessing Risk and Reducing Disaster, 5th Edn., Routledge, New York, 2009.

Tarvainen, T., Jarva, J., and Greiving, S.: Spatial pattern of hazards and hazard interactions in Europe, in: Natural and Technological Hazards and Risks Affecting the Spatial Development of European Regions, edited by: Schmidt-Thomé, P., Geological Survey Of Finland, Espoo, Finland, 42, 83-91, 2006.

Thirumalaivasan, D., Karmegam, M., and Venugopal, K.: AHPDRASTIC: software for specific aquifer vulnerability assessment using DRASTIC model and GIS, Environ. Model. Softw., 18, 645-656, 2003.
UNDP - United Nations Development Programme: Reducing Disaster Risk: a Challenge for Development, United Nations Development Programme, Bureau for Crisis Prevention and Recovery, New York, 146 pp., 2004.

Varnes, D. J.: Landslide types and processes, Highway Res. Board Spec. Rep., 29, 20-47, 1958.

Varnes, D. J.: Landslide Hazard Zonation: a Review of Principles and Practice, UNESCO - The United Nations Educational, Scientific and Cultural Organization, Paris, 63 pp., 1984.

Wilhite, D. A. and Glantz, M. H.: Understanding: the drought phenomenon: the role of definitions, Water Int., 10, 111-120, 1985.

Zhou, Q., Mikkelsen, P. S., Halsnæs, K., and Arnbjerg-Nielsen, K.: Framework for economic pluvial flood risk assessment considering climate change effects and adaptation benefits, J. Hydrol., 414, 539-549, 2012. 